\title{
Desintegración del hormigón causada por un árido que contenla pirrotita
}

Una de las condiciones que debe tener un árido para su empleo en la obtención del hormigón, es que no reaccione con el cemento dando lugar a productos de mayor volumen que posteriormente lo alteren.

Entre los áridos, considerados como nocivos, se encuentran algunas variedades de cuarzo amorfo tales como: ópalos, cristobalitas, tridimitas, andesitas, etc., que se combinan con los álcalis que contiene el cemento y dan productos expansivos que destruyen al hormigón. Afortunadamente dichos áridos no son frecuentes; en España no se conoce ningún caso en el que se haya producido este tipo de reacción álcali-árido. En Estados Unidos, en cambio, se ha dado y ha sido muy estudiado este tipo de reacción.

Los álcalis del cemento, e incluso los procedentes de otros áridos que se encuentran accidentalmente en el hormigón, también pueden reaccionar con determinados tipos de dolomitas que aparecen en forma de cristales rómbicos en una matriz microcristalina de calcita y arcilla; los contenidos de caliza más favorables a la desdolomitización son de $50 \%$. En algunos casos los productos de descomposición de la dolomita, en el hormigón, se detectan en forma de hidróxido de magnesio.

En España aproximadamente la mitad de su terreno es yesífero y el yeso reacciona con el cemento. En la obtención del cemento y para regular su fraguado se le añade yeso en el molino del clínker. La totalidad del yeso añadido reacciona antes de las 24 horas con parte del aluminato tricálcico que contiene el cemento y da ettringita; otra parte del aluminato tricálcico queda libre para reacionar si posteriormente se encuentra en presencia de sulfatos, procedentes de áridos o aguas en contacto con la pasta de cemento. Sı accidentalmente se añadió yeso como árido, éste producirá más ettringita después de que el homigón ya endureció provocándole grietas y fisuras.

Las piritas y otros sufuros en contacto con la atmósfera pueden oxidarse a sulfatos, que también reaccionarían con el aluminato tricálcico del cemento dando ettringita expansiva que desintegraría al hormigón.

La peligrosidad potencial de las piritas aumenta al ser mayor su contenido en hierro, por ser más fácilmente oxidables por los agentes atmosféricos. Para distinguirlas es conveniente recordar sus características, que son las siguientes:

La pirita, $\mathrm{FeS}_{2}$, tiene color amarillo dorado, cristaliza en forma de cubos o de pentagonododecaedros en el sistema cúbico, su dureza está comprendida entre 6 y 6,5 ; conduce bien el calor y la electricidad, es insoluble en ácido clorhídrico y soluble en ácido nítrico concentrado; en sus yacimientos se suele encontrar acompañada de hematites parda o de limonita. Por su apariencia de dureza e inalterabilidad podría ser un buen árido; sin em- 
bargo debido a las impurezas que la acompañan y defectos de constitución de su estructura se conocen casos en que se ha descompuesto por distintas causas, como luego veremos, que la hacen inaceptable como árido.

La marcasita, $\mathrm{FeS}_{2}$, de color amarillo con tonalidades verdosas, cristaliza en el sistema ortorrómbico, y su dureza es semejante a la de la pirita, y también es insoluble en ácido clorhídrico y más soluble que la pirita en ácido nítrico, ya que da burbujas con el ácido diluido; se sabe que es más atacable que la pirita por los agentes atmosféricos y, por lo tanto, aún es menos aconsejable su uso como árido.

La pirrotita, $\mathrm{FeS}$, aunque los contenidos de hierro son menores de los estequiométricos y son del orden de 7:7 ó 11:12, cristaliza en el sistema hexagonal, su dureza es del orden de 4,6 a 4,7. Es magnética, cualidad que la distingue de la pirita y de la marcasita y, al contrario que éstas, es soluble en ácido clorhídrico con desprendimiento de sulfuro de hidrógeno.

Es muy poco estable frente a los agentes atmósféricos. Como no tiene interés industrial para la fabricación del ácido sulfúrico, como les sucede a la pirita y a la marcasita, es poco conocida.

La oxidación de los sulfuros de hierro es citada en todos los ibros de mineralogía. La destrucción de los especímenes de marcasita y de pirrotita es frecuente en las colecciones de minerales. Particularmente la pirrotita se autopulveriza y forma ácidos que destruyen a las etiquetas que se emplean para su clasificación; muy posiblemente el ácido formado es el sulfúrico.

Hay pocos antecedentes del uso de piritas como áridos. Recientemente en Australia se utilizó una cuarzita con pirita como árido en la construcción de una presa.

La desintegración del hormigón de un túnel de desvío de dicha presa fue atribuida a la oxidación de la pirita provocada por la acción de bacterias púrpuras de los tipos cromátium y/o cloróbium, así como a la disminución del pH que impidió el uso del agua de la presa.

La acción bacteriana es muy conocida de los técnicos en saneamiento y suele darse en redes de alcantarillado; hay una serie de bacterias, tales como los tiobacilos, sulfurilos, etc., que descomponen las proteínas y convierten el azufre que contienen en sulfuro de hidrógeno y ácidos sulfuroso y sulfúrico que atacan al hormigón.

El caso más conocido y estudiado de uso de piritas como árido se dio en la canalización del Támesis. Se utilizaron piritas de distinta procedencia y composición que dieron lugar a feas coloraciones pardas, atribuidas a la formación de óxidos de hierro y unas pequeñas picaduras formadas por microexplosiones "popouts" debidas a la oxidación de las piritas; ambos motivos fueron causa del rechace de las piritas como áridos.

La bibliografía existente en manuales y revistas de la especialidad (1), (2), (3), (4), (5), (6), (7) y (8) insiste en que las piritas no deben de utilizarse como áridos, aunque salvo los casos citados, no suelen decir los porqués y parece ser que se prevía que darían malos resultados por motivos teóricos.

Dichos motivos pueden ser los siguientes:

Aunque la oxidación del ion sulfuro a azufre, anhídrido sulfuroso, anhídrido sulfúrico, no es una reacción que dé altos rendimientos en ausencia de catalizadores y de condiciones determinadas de temperatura, como se estudia en la obtención del ácido sulfúrico, se puede comprobar que da en el caso de las disoluciones de sulfuro de hidrógeno que en presencia de aire terminan dando la reacción de sulfatos. En el caso de la pirita, marcasita y pirrotita vimos que podían y que de hecho se oxidaban a sulfatos en presencia de los agentes atmosféricos. 
En la química analítica se estudia la precipitación, en medio básico, del sulfuro ferroso con sulfuro amónico y se dice que el sulfuro ferroso así precipitado puede oxidarse, en presencia del aire, a sulfato básico de hierro.

En el Instituto Eduardo Torroja se hicieron estudios sobre algunos edificios que presentaban grietas. Dichos edificios habían sido construidos con un árido procedente de una cantera que, con motivo de unos cambios en su instalación de preparación de áridos, se obtuvo de un frente distinto del utilizado usualmente. El árido estaba constituido por una caliza de color oscuro y con pequeñas inclusiones de pirita. El nuevo frente fue utilizado durante unos meses en el año 1970, el material extraído tenía una coloración negra y fue empleado por los constructores de la zona, ya que la cantera tenía una buena instalación de machaqueo y facilidades de acceso.

Al cabo de un año aproximadamente los edificios construidos con el árido procedente del nuevo frente presentaban grietas y fisuras que obligaron a tomar las medidas oportunas.

En el hormigón procedente de dichos edificios se encontró un árido negro que tenía propiedades magnéticas y que era untuoso al tacto. Al tratarlo con ácido clorhídrico desprendía un fuerte olor a sulfhídrico.

Los análisis químicos realizados del árido, obtenido del hormigón y también del traído de la cantera, eran variables para cada muestra, lo cual demostraba su falta de uniformidad; uno de los resultados obtenidos fue el siguiente:

$$
\begin{aligned}
\mathrm{SiO}_{2} & =47,10 \\
\mathrm{Al}_{2} \mathrm{O}_{3} & =16,90 \\
\mathrm{Fe}_{2} \mathrm{O}_{3} & =9,60 \\
(\mathrm{Fe} 0 & =7,60) \\
\mathrm{CaO} & =10,10 \\
\mathrm{MgO} & =2,40
\end{aligned}
$$

$$
\begin{aligned}
\mathrm{K}_{2} \mathrm{O} & =2,20 \\
\mathrm{Na}_{2} \mathrm{O} & =0,60 \\
\mathrm{SO}_{3} & =0,50 \\
\mathrm{~S}^{=} & =4,50 \\
\mathrm{CO}_{2} & =5,7 \\
\mathrm{H}_{2} \mathrm{O} & =0,3
\end{aligned}
$$

El difractograma de la figura 1, obtenido a partir de una muestra del árido negro, mostraba los siguientes componentes: carbono grafítico, ortaclasa, anortita, cuarzo, calcita, mica, marcasita y pirrotita.

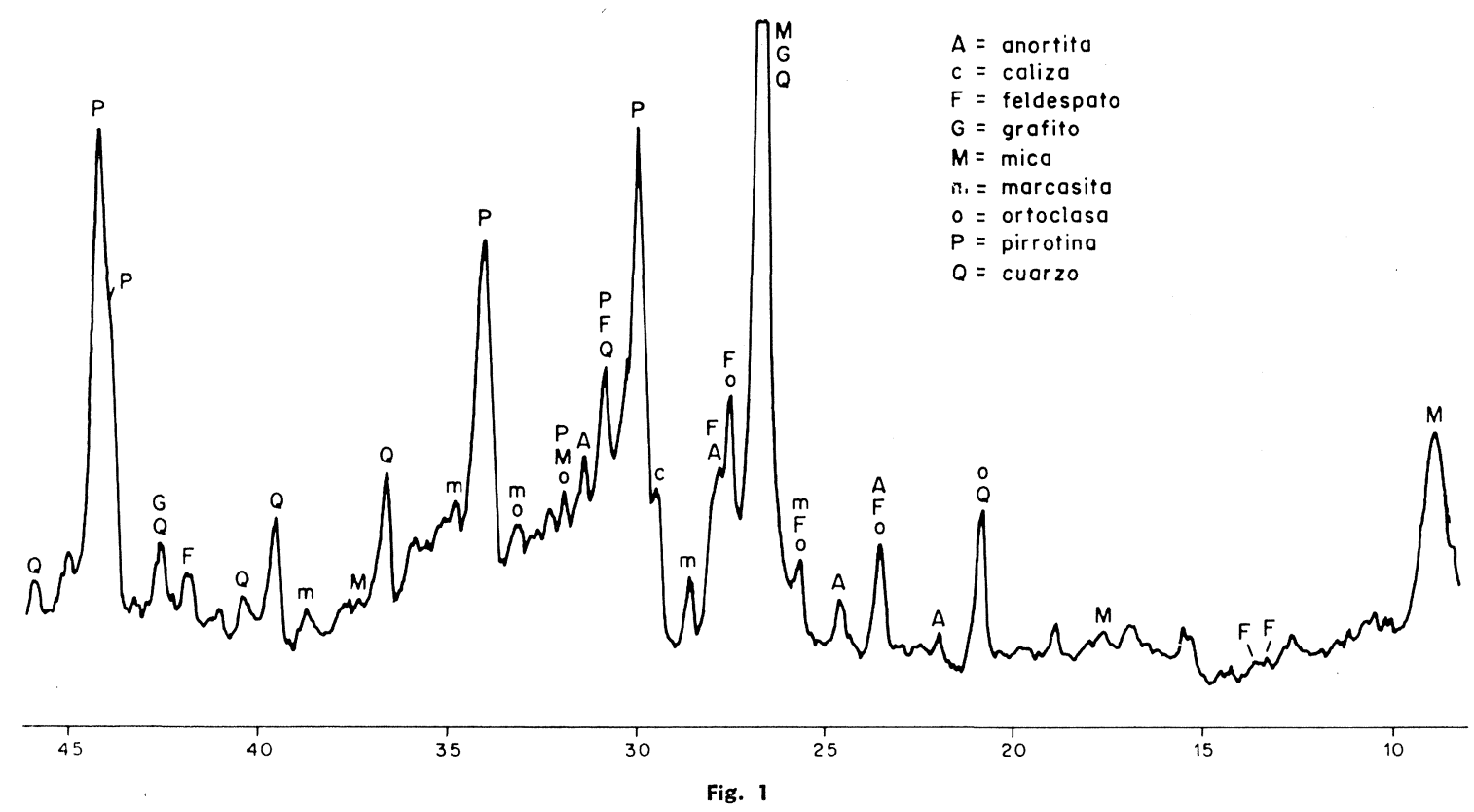


El árido negro, en el hormigón, presentaba en ocasiones una aureola blanquecina que, según el difractograma de la figura 2, contenía ettringita. La fotografía de la figura 3 muestra la aureola.

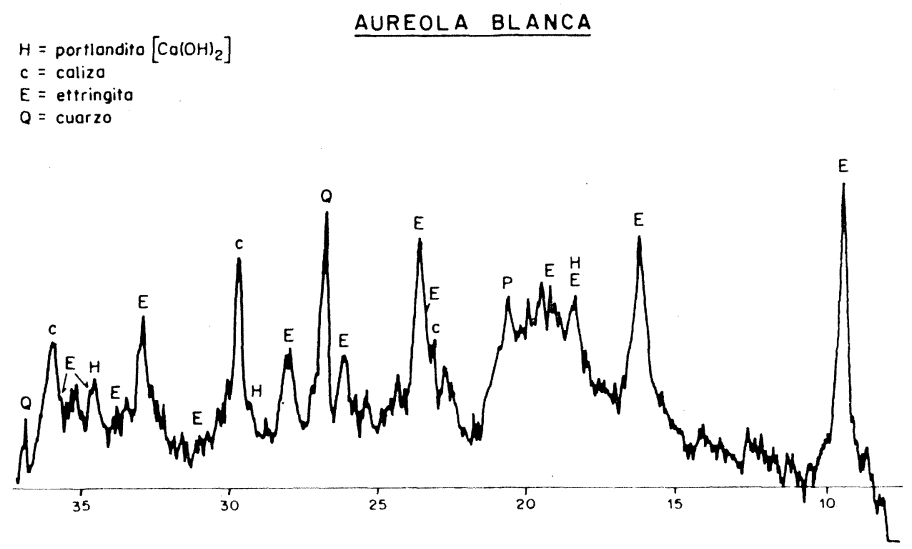

Fig. 2

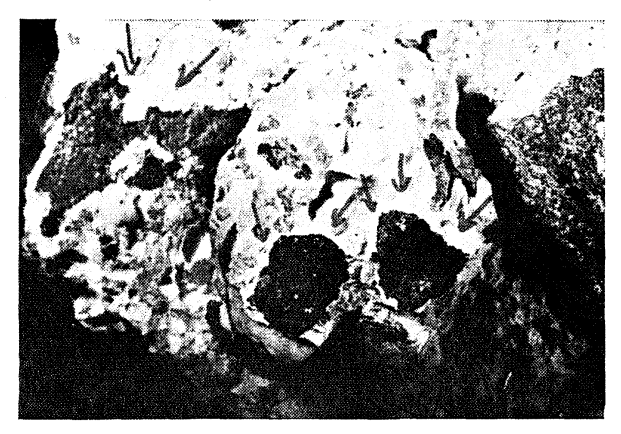

Fig. 3

Igualmente se efectuó un raspado de la pasta que rodeaba al árido negro y su difractograma dio también ettringita (fig. 4).

\section{CEMENTO PROXIMO AL ARIDO}

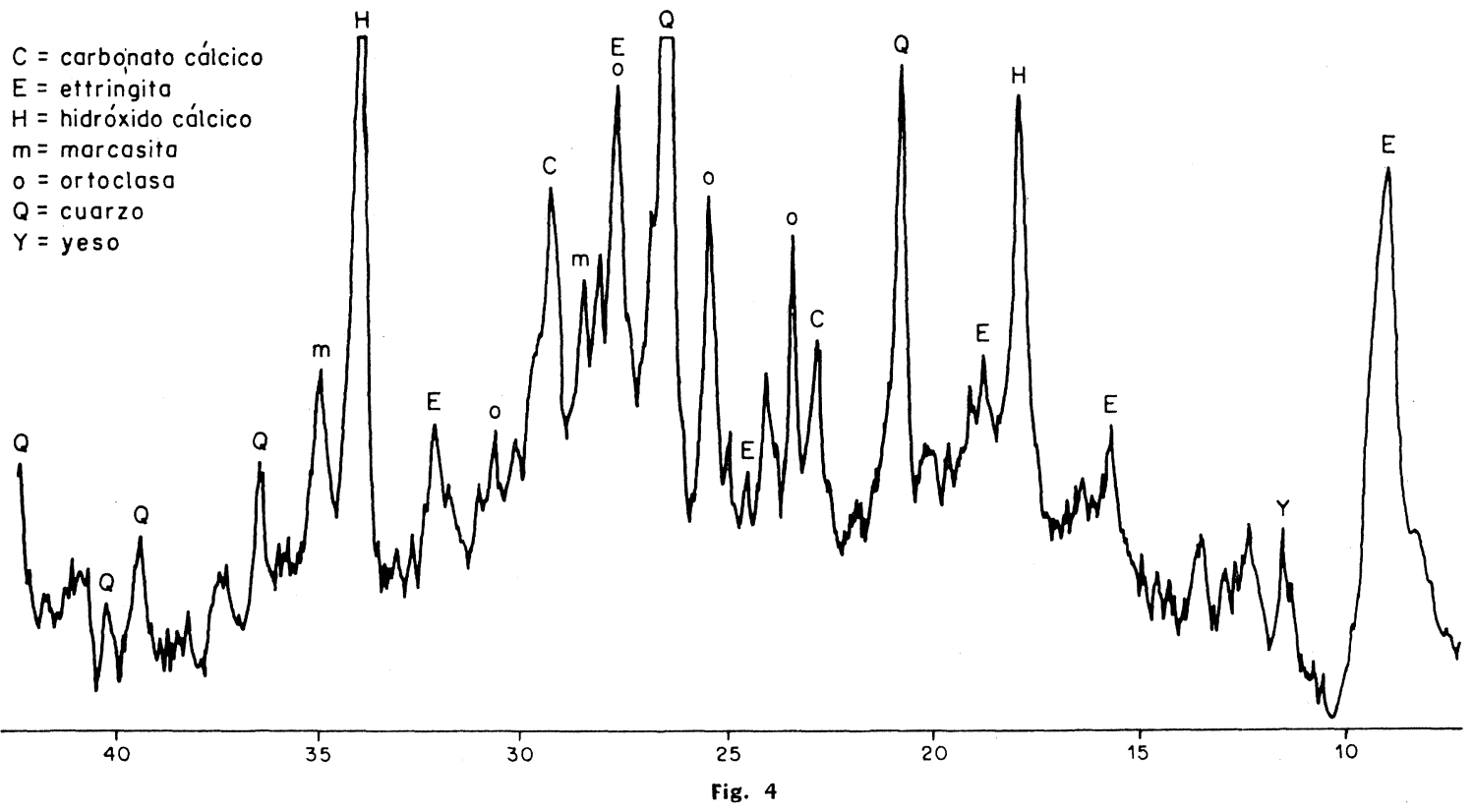

Las grietas observadas en las estructuras y en los edificios eran, según los casos, poligonales o longitudinales. Se presentaban preferentemente en los exteriores y en zonas bien aireadas, lo cual indicaba que la reacción de oxidación de la pirrotita contenida en el árido se favorecía por el contacto con la atmósfera y por subidas de temperatura ambiente. 
Parece ser que la reacción de expansión producida por la formación de ettringita es neutralizada, en parte, por la contrapresión debida al peso de la estructura, y por eso, las grietas eran mayores en las zonas elevadas, tales como las azoteas, y en los salientes, tales como voladizos, balcones y escaleras, y menores, en los pisos más bajos.

El aislamiento del aire y del calor atenuaba los defectos que, por lo mismo, no existían en la cimentación.

Con árido procedente del nuevo frente se confeccionaron una serie de probetas que, por falta de material, no se pudo añadir finos y quedaron con coqueras; la mitad de las probetas, para tapar las coqueras, se refrentaron con pasta de cemento.

La mitad de ambos tipos de probetas se colocó en cámara húmeda a $20^{\circ} \mathrm{C}$ y el resto se calentó en cámara húmeda a $50^{\circ}-60^{\circ} \mathrm{C}$ en ciclos de 8 horas diarias durante 24 días.

Las probetas mantenidas a $20^{\circ} \mathrm{C}$ se mantuvieron inalteradas a los 3 meses. Las probetas que sufrieron ciclos térmicos se agrietaron en su totalidad y las refrentadas manifestaron hinchazones en las partes refrentadas (fig. 5).

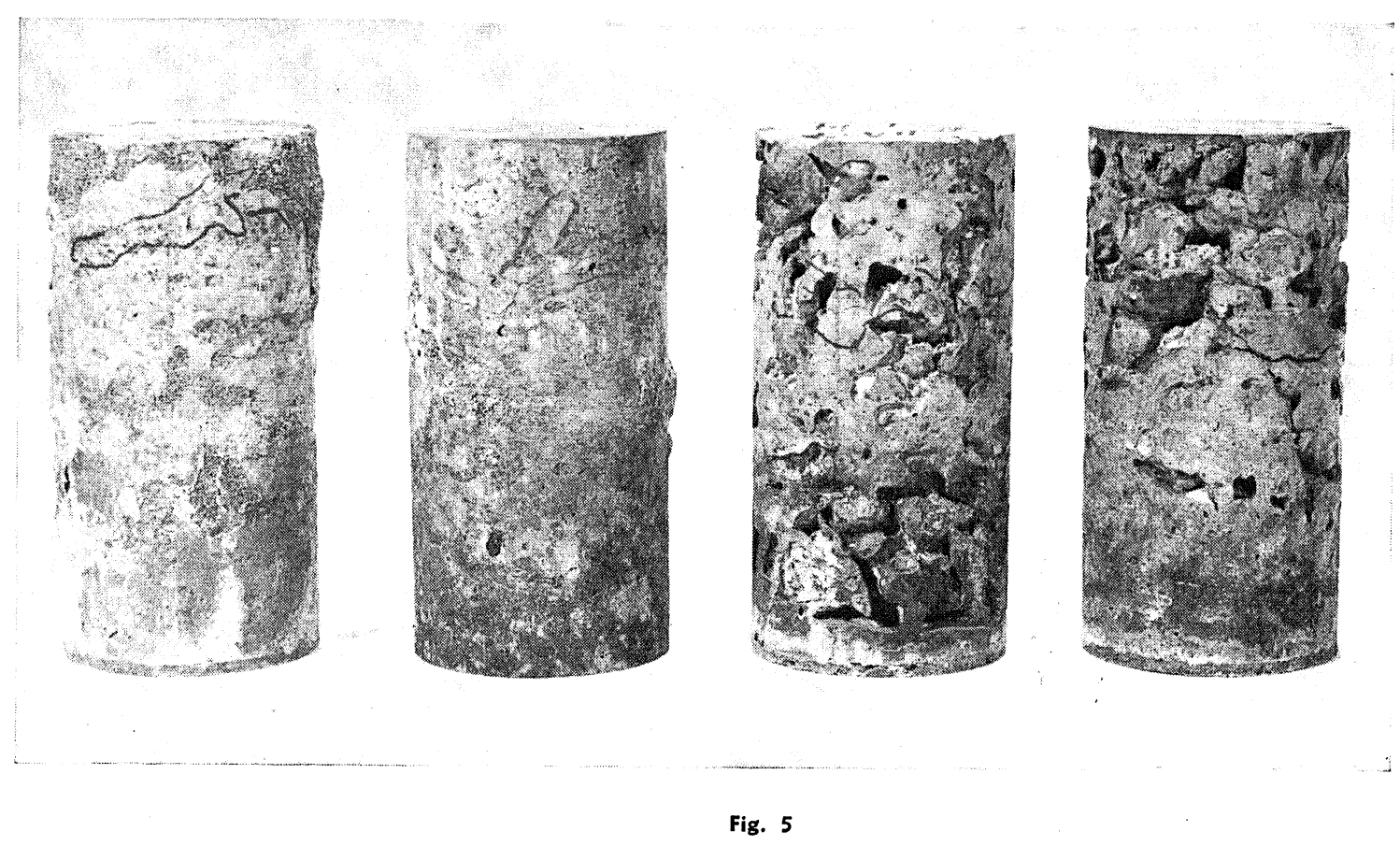

Para demostrar la posibilidad de formación de ettringita, a partir de aluminato tricálcico y de una disolución de sulfhídrico, se efectuó una prueba en un matraz de vidrio de un litro de capacidad que contenía dos gramos de aluminato tricálcico y un litro de disolución saturada de sulfhídrico, y el conjunto se mantuvo en agitación con un agitador magnético.

En el difractograma obtenido de los sólidos a las 24 horas (fig. 6) se observa abundante formación de aluminato tetracálcico hidratado, carbonato cálcico y trazas de ettringita. A la semana se obtiene un difractograma prácticamente igual (fig. 7). A las tres semanas se observa en el difractograma una fuerte descomposición del aluminato tetracálcico hidratado, aumento en la formación de carbonato cálcico y una gran proporción de ettringita (fig. 8). 


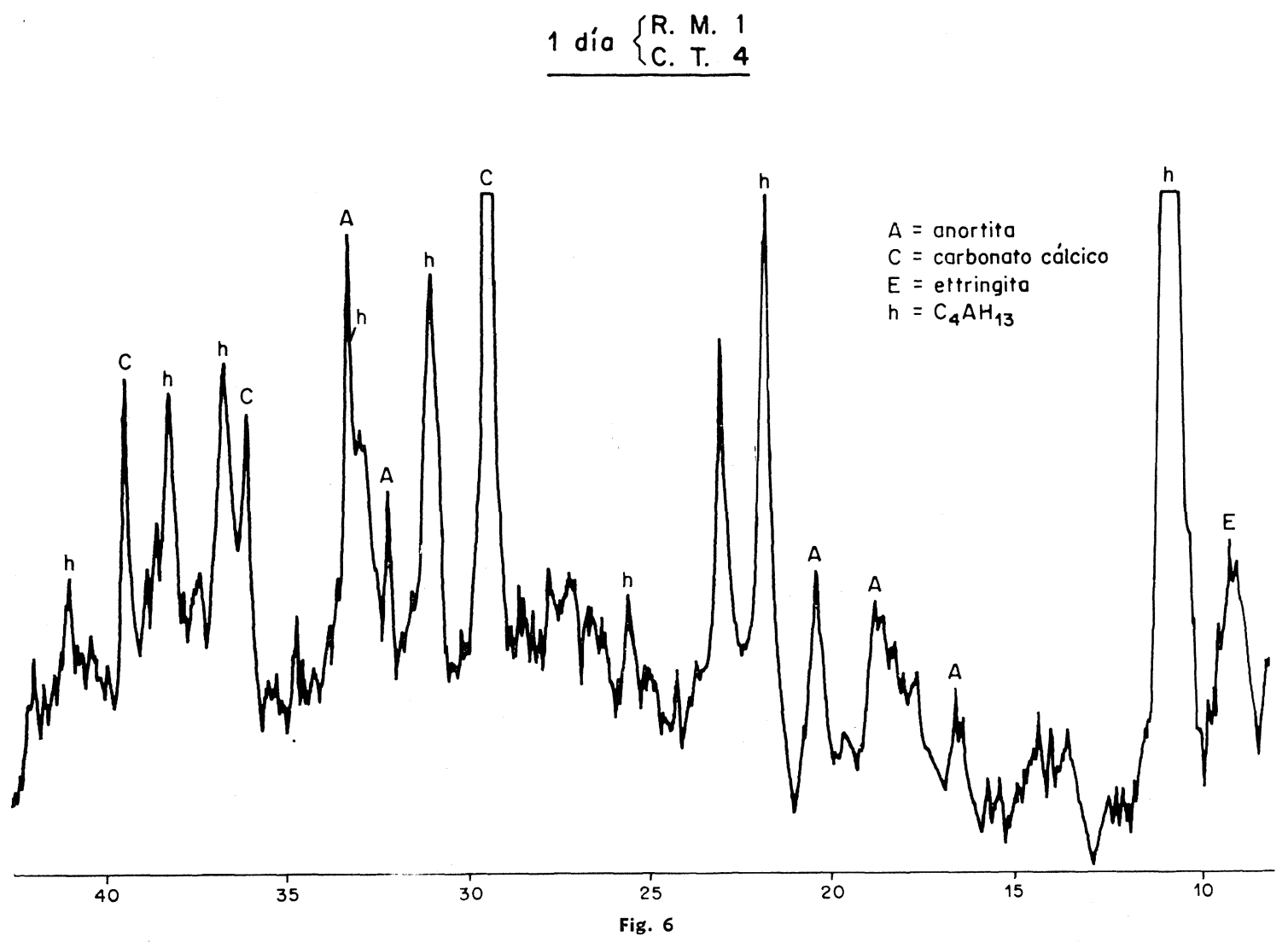

1 semana $\begin{cases}R . & M .4 \\ C . & T .\end{cases}$

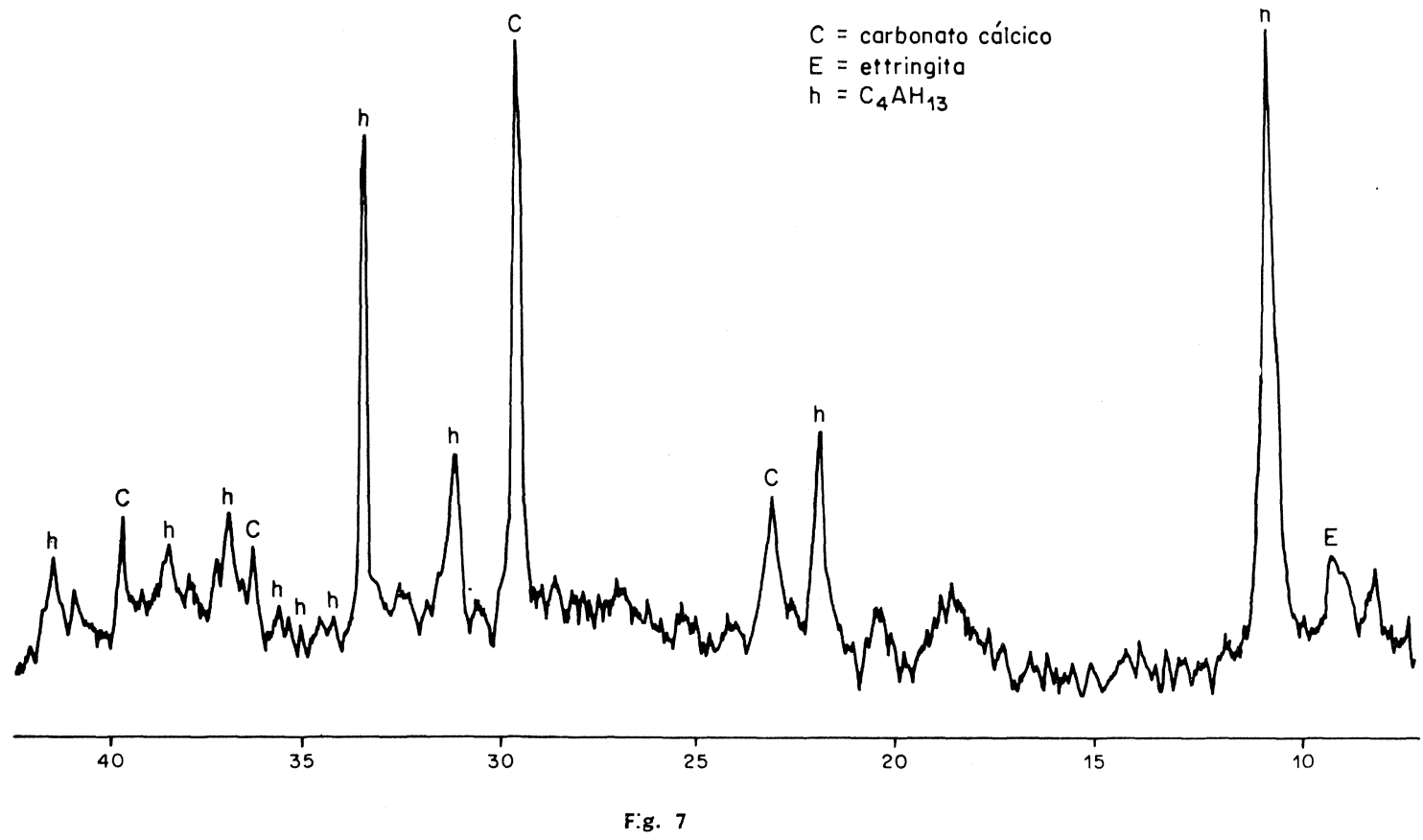




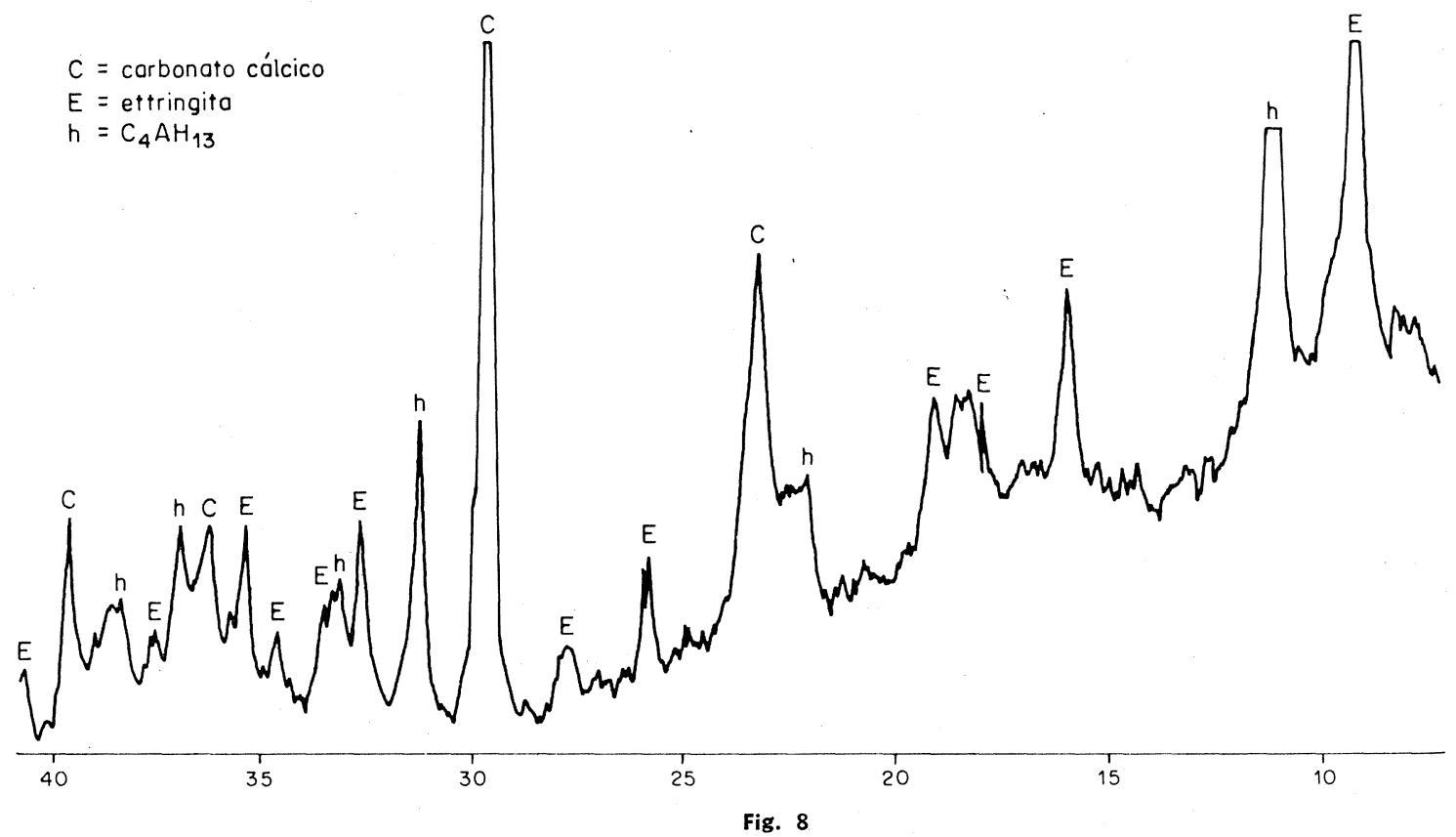

A las cuatro semanas se observa un aumento en la formación de ettringita que se presenta mejor cristalizada (fig. 9).

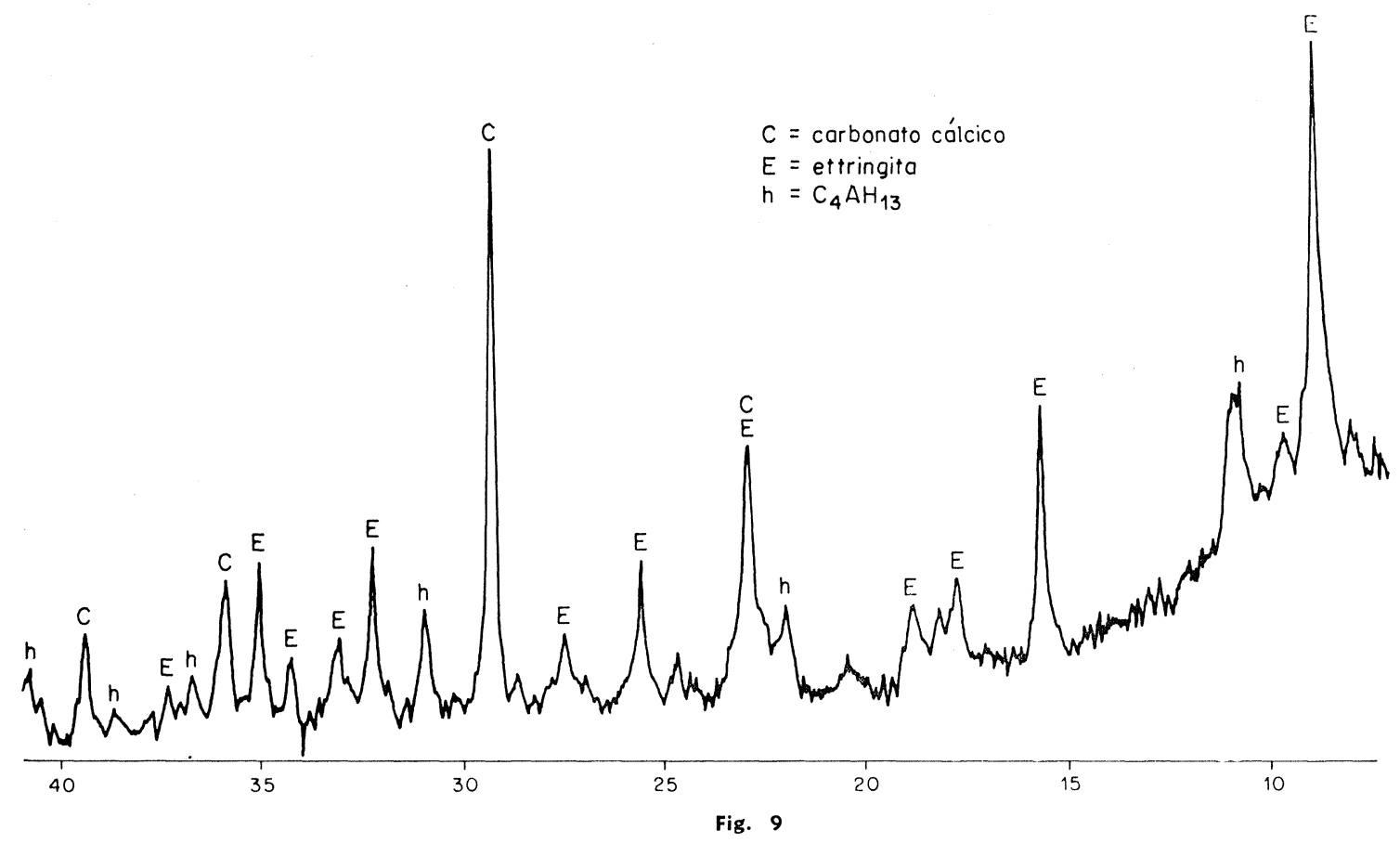


Para demostrar la posibilidad de formación del ácido sulfúrico a partir del sulfhídrico, se mantuvo en agitación, en contacto con el aire, una disolución de sulfhídrico que a las tres semanas dio la reacción de sulfatos.

Con lo anterior queda demostrada la nocividad de la pirrotita, aun en la pequeña proporción $(10 \%)$ en la que se encuentra en el árido.

Igualmente se demuestra que la expansión que sufre el hormigón se debe a la formación de ettringita y también la posibilidad de formación de sulfatos por oxidación del ácido sulfhídrico y la formación de ettringita cuando se encuentra en presencia de aluminato tricálcico; por extensión se ve la posibilidad de oxidación de los sulfuros, hecho comprobado por la práctica.

La consecuencia general es que no hay que descuidarse en la vigilancia de los áridos y que es conveniente conocer su composición cada vez que se observen cambios en el material.

\section{B I B L I O G R A F I A}

(1) E. G. Swenson and V. Chaly.: "Journal of the American Concrete Institute", vol. 27, n." 9, 987-1.002, mayo 1956.

(2) Roger Rhoades and Richard C. Mielenz.: “Symposium on Mineral Aggregates”, 39 , junio 1948.

(3) ACI Manual of Concrete Practice-part. I, 201-25, 1970.

(4) Proceedings, ASTM, vol 54, pág. 1.216, 1954.

(5) Disposiciones del Comité Alemán para hormigón armado.: F. Aridos para Hormigones DIN 4226 , apart. II, párrafo 5. 3, 1955.

(6) KleINLOGEL.: "Influencias físico-químicas sobre los hormigones en masa y armados”, págs. $247,258$. Ed. Labor, 1955.

(7) OldRICH VAlenta.: “Chemistry of Cement-Proceedings of the Fifth International Symposium”, página 202, Tokyo 1968.

(8) J. Moum, T. Tosenquist.: J. Amer. Conc. Ins., septiembre 1959. 